\title{
PHILOSOPHY
}

Borisenko O.A., Fomina M.N.

\section{GLOBALIZING CULTURE AS THE ESSENCE AND THE PHENOMENON OF GLOBALIZATION}

\author{
Borisenko O.A., Russia, Transbaikal state university, Associate \\ Professor of Philosophy, PhD of philosophic \\ Fomina M.N., Transbaikal state university, Professor of \\ Philosophy, Doctor of Philosophy iranchuk N. N., Candidate of pedagogical \\ Sciences of Ukrain (doctor of philosophy), Rivne state humanitarian \\ University
}

\begin{abstract}
In this article you can see Globalizing culture as the essence and the phenomenon of globalization. Political, economic changes not only affect the modernization of cultural processes, but also help them, because culture is not only always been a reflection of social processes, but also a factor of their formation and development. In a globalized world culture became comprehended not only as a local (culture of individual countries, ethnic groups, etc.), but also as a global one, which refers to world culture, having the general trends that determine the course of human development.

Keywords: globalization, culture, philosophical, world.

Введение

Осмысление глобализации через философские понятия сущность и явление дает возможность проанализировать природу глобализирующейся культуры. Это обусловлено тем, что сущность процесса глобализации раскрывается непосредственно не только в экономических, политических, но и в культурных явлениях.

Если сущность (суть) глобализации позволяет понять источник изменений, трансформаций, модернизации, то явления «демонстрируют» глобализацию через экономические, политические, культурные и пр. образы. Так как глобализация раскрывается через взаимосвязь и
\end{abstract}




\section{Social Science and Humanity \#3 2016}

последующую взаимозависимость ее субъектов (от стран до конкретных сфер деятельности), от их сближения до образования единой сферы деятельности и интересов, то это уже является основанием говорить о взаимной ответственности сторон за единое (планетарное) информационное, культурное (и т.п.) пространство. Глобализация, будучи процессом интернационализации, проявляется в различных сферах жизни, в том числе и в культурной.

Материал исследования

Как отмечает А.Н. Чумаков, становление глобалистики как междисциплинарной сферы[1], как сферы научных исследований и целостного миропредставления[1] отмечено в конце XX века, когда феномену глобализации стали в научных исследованиях уделять особое внимание.

«Сформировавшись как сфера теории и практики»[1], глобалистика свое внимание направляет на глобализацию и глобальные проблемы. Определяя суть понятий «глобализация» (как «многовековой естественноисторический процесс»), «глобальные проблемы» (как «закономерный результат» данного процесса), А.Н. Чумаков отмечает, что «глобалистика - сфера теории и практики, в центре внимания которой находятся глобализация и глобальные проблемы» что позволяет ему заключить - ее «предметом является целостность мира»[1].

Следствием осмысления изменяющегося мира стало то, что в научном языке появились и стали обсуждаться такие понятия как «глобальный мир», «глобальное мировоззрение», «глобальное сознание», «глобальное человечество», «глобальная культура»[2], «глобализирующийся мир» и «глобализируемый мир»[3].

По замечанию А.Н. Чумакова, понятие глобализации «употребляется для характеристики интеграционных и дезинтеграционных процессов планетарного масштаба в области экономики, политики, культуры»[2]. При этом он пишет, что для анализа понятия глобализации необходимо учитывать, что она представляет собой «отражение динамики социально-экономических и политических перемен в мировом масштабе»[4].

Анализируя работу И. Мазура и А.Н. Чумакова «Процессы глобализации и наука глобалистика», У. Гэй определил главные темы глобалистики, к которым он отнес: «1) процессы глобализации; 2) мировые проблемы, вызванные процессами глобализации; 3)увеличение положительных и сокращение отрицательных последствий этих процессов для людей и биосферы»[5].

О.В. Малюкова[6], учитывая, что глобализация представляет собой одну из форм интеграции, определяет ее номинации и признаки. К номинациям О.В. Малюкова относит: 


\section{Social Science and Humanity \#3 2016}

- интеграцию социальных институтов (учреждений, организаций);

- деятельность этих институтов;

- знания, которые необходимы для этой деятельности;

- идеалы (ценностные ориентиры), которые определяют мотивы деятельности;

- нормы поведения, которые определяются идеалами;

- ценности, которые создаются в процессе деятельности и реализации ее идеалов (ценностных ориентиров, идеологических установок).

Не сложно заметить, что О.В. Малюкова по той причине определяет «деятельность» как номинацию, так как это позволяет ей «придать» деятельности социальных институтов в условиях глобализации особую значимость и роль.

К признакам глобализации она относит:

- всесторонность (многоаспектность) - интеграция в доминирующих сферах(политическая, экономическая, социо-культурная) социальной жизни;

- массовость (демократичность) - вовлечение и активное участие в интеграционном процессе всех социальных слоев;

- планетарность (глобальность) - тенденция к распространению интеграционных процессов в мире;

- спонтанность (самопроизвольность, самоорганизация) отсутствие у интеграционных процессов внешнего организатора;

- хаотичность - неупорядоченность интеграционных процессов.

Можно предположить, что О.В. Малюкова определяет как положительные, так и негативные стороны признаков глобализации. Но при этом стоит заключить, что, как бы, ни оценивался данный процесс, в сфере внимания остаются глобальные проблемы.

Таким образом, «глобальность» - эта проблема, которая, по словам М.А. Чешкова может интерпретироваться «как единое обобщающее понятие», которое охватывает как абстрактный, так и эмпирический уровень познания[7].

C учетом сказанного, M.А. Чешков предлагает и методологические подходы к исследованию данного как феномена, так и понятия. Он исходит из того, что предмет исследования является одним из составных звеньев в логической цепочке «человеческий универсум миробытие - глобальность», где глобальность представляет собой разнообразные связи и отношения между структурными элементами миробытия. Это позволяет говорить о том, что человеческий универсум, определяет антропологическую природу глобальности через миробытие.

Таким образом, можно заключить, что при исследовании глобальности необходим антропологический подход. 


\section{Social Science and Humanity \#3 2016}

Следующие методологические параметры, которые выделяет А.М. Чешков, это гносеологический и онтологический. Если гносеологический обосновывает познавательный процесс, то онтологический определяет отношения различных неравенств (политических, культурных, экономических и т.п.).

С учетом сказанного, А.М. Чешков заключает, что субъект глобальности, будучи антропологическим, должен быть описан при помощи социально-культурно-антропологических понятий[7]. Данное заключение обосновывает рассмотрение объекта данного исследования как глобализирующаяся культура.

Другим параметром глобальности, по нашему мнению, следует считать фактор общения. Х.А. Барлыбаев считает, что его роль увеличивается в связи со стремлением человечества к глобальному единству[8], так как человек нацелен на формирование новых человеческих общностей. По мнению Д.Ж. Марковича, глобализация, способствуя человеческому объединению, создает и новые глобальные сообщества[9], одним из которых и является Шанхайская организация содружества. Это объясняется тем, что глобализация способствует мировой и региональной интеграции.

В заключении данного раздела необходимо остановиться на следующих концептуальных положениях:

- теория глобалистики представляет собой осмысление глобализационных процессов, протекающих во всех сферах общественной жизни;

- исследование инновационных, трансформационных и прочих процессов в сфере глобализирующейся (глобальной) культуры на уровне глобалистических подходов находится на начальном этапе.

Обсуждение материала

Как отмечает В.М. Межуев «природа философской рефлексии такова, что любой ее объект раскрывается как феномен культуры»[10].

Оперируя понятием «идея культуры», к которому В.М. Межуев обращается для обоснования «систематического единства» и «типологического различия», где под первым он мыслит множество форм культур, а под вторым - «историческое множество, образуемое культурами разных стран, эпох и народов»[10], становится возможным обоснование глобализирующейся культуры.

Но, если следовать за мыслью В.М. Межуева далее, то здесь мы сталкиваемся с тем, что глобализирующаяся культура может быть рассмотрена как понятие или как идея. Если идея включает в себя нечто большее, чем понятие[10], то, следовательно, речь уже будет идти о том, что необходимо обосновать «вопрос о самой возможности»[10] существования культуры, в нашем случае - глобализирующейся культуры. 


\section{Social Science and Humanity \#3 2016}

И если В.М. Межуев отмечает, что «идея культуры - продукт своего времени: она трансформируется с каждым новым поворотом европейской культуры»[10], то можно предположить, что идея глобализирующейся культуры - продукт XXI века.

Следовательно, необходимо осмыслить становление идеи глобализирующейся культуры.

Соотношение культуры и глобализации сегодня представлено в философии, культурологии, в философии культуры и в др. областях научного знания не достаточно широко.

О глобализации культуры можно говорить там и тогда где и когда появляются инфраструктуры и институты передачи, воспроизводства и восприятия культуры в глобальном масштабе (если телевидение, то речь о международном рынке телевизионных программ, траснациональные системы и каналы вещания)[11].

Современная культурная глобализация содержит несколько параметров: новые глобальные инфраструктуры, которые обеспечивают большие возможности проникновения элементов той или другой культуры через границы государств; увеличение коммуникаций в культурном бизнесе как основное экономическое содержание глобального культурного взаимодействия; преобладание многонациональной индустрии культуры[11].

Сказанное позволяет заметить, что целостность глобализирующейся культуры характеризуется:

- способностью вступать в диалог;

- быть самореализованой, признавая это право и за другими;

- обладает способностью сохраняться в информационной системе (в отличие от традиционной, которая сохраняется в памяти народа);

- обладает содержательным многообразием (так как представлена на уровне множества культур); глобализации.

- приобщение к ней достигается благодаря знаниям о

Учитывая, что глобализирующаяся культура представляет собой единство в многообразии, то возникает вопрос о том, какими средствами (приемами и методами исследования) может быть доступен для понимания ее смысл.

Второй вопрос, который может быть поставлен, состоит в том, что носителем любой культуры является «кто-то», от отдельного человека до нации. Но есть еще и такое понятие, которое использует В.М. Межуев для характеристики массовой культуры как «массы»[10].

Анализируя природу глобализационных процессов X.A. Барлыбаев, обосновывает, что они направлены на устойчивое развитие, исходя из параметров природы человека. Это позволяет ему рассматривать как один из параметров - духовную жизнь человека. А 


\section{Social Science and Humanity \#3 2016}

сфера глобализации, охватывающая его - глобализация культуры. Учитывая свою теорию устойчивого развития, Х.А. Барлыбаев заключает, что переходом к устойчивому развитию будет являться «конструктивное взаимодействие культур»[8].

С учетом данного методологического подхода, можно уточнить, что культурная глобализация, это отражение динамики культурных процессов в формирующейся глобальной культурной системе.

Осмысливая концепцию глобализирующегося мира В.А. Колесников отмечает, что сегодня для философии необходимо выработать новые цивилизационные стратегии, которые позволят осмыслить научную, культурную, духовную составляющую[3]. Это объясняется, по его мнению тем, что именно философия может не только осмыслить сущность современного бытия, но и проанализировать конкретную реальность.

Как показала практика, глобализация, отражая процесс создания глобального общества, «способствует объединению человечества»[9], происходящему на фоне политических, экономических, культурных процессов. Этому способствует глобальная система, которая, по замечанию Д.Ж. Маркович[9], характеризуясь определенной самостоятельностью, «проявляется посредством ...экономической глобализации, глобализации культуры» и др. Если понятие «глобализация культуры» рассматривать как процесс развития культуры в условиях глобализации, то «глобализирующаяся культура» - явление, отражающее нормы и принципы, ценностные ориентации поведения и отношения к миру - пространству совместного гармоничного проживания с позиций общечеловеческой безопасности. Этот контекст позволяет осмыслить морально-нравственные регуляторы в сфере межнациональных (межгосударственных) отношений, обращение к которым необходимо в условиях глобализации, так как именно культурное (как традиционное так и информационное) пространство создает для этого все условия благодаря культурному диалогу.

Для подтверждения своих слов Д.Ж. Маркович ссылается на организацию ООН, которая призвана решать вопросы разногласий. Но стоит сказать, что в отношении ШОС - ситуация другая, так как в Декларации Содружества уже заложены принципы соблюдения, согласия, соучастия и пр. И если пользоваться понятием Д.Ж. Маркович «культура мира», то стоит заметить, что ШОС можно рассматривать как зарождающийся показатель культуры мира, построенный на общечеловеческих принципах.

При этом стоит заметить, что именно диалогу при формировании культуры мира отводится ведущее значение. Д.Ж. Маркович отмечает, что становится реализацией «нового способа жизнедеятельности»[9], так как он становится способом разрешения «противоречий мирным путем». 


\section{Social Science and Humanity \#3 2016}

Как отмечает А.Н. Чумаков[12] совпадение культурноцивилизационных явлений у различных народов способствует активному становлению и развитию атмосферы сотрудничества взаимопонимания. А дальше он замечает, что «В последние годы можно наблюдать, как Китай, Индия, Россия и Бразилия, обладая самобытными культурами, но наращивая темпы цивилизационного развития, также становятся в ряд тех стран, между которыми улучшаются и усиливаются культурноцивилизационные связи и конструктивное сотрудничество».

Анализируя работу Всемирного культурного форума, который проходил в 2014 г. в Китае, А.Н. Чумаков отмечает, что лейтмотивом дискуссий было признание того факта, что не только судьба объединяет глобальное сообщество, но и культурное взаимодействие между странами, которое основано на признании принципов сосуществования различных культур. Это, как замечает А.Н. Чумаков и можно считать одним из факторов роли культуры не только в сохранении мира, но и прогресса человечества[13].

Поэтому, учитывая, что глобалистика направлена на исследование ни только причин глобальных изменений, но и ее проблем[5], обращение к современной цивилизации и диалогу культур вполне обоснованно, тем более, что он становится одним из инструментов в деятельности международных организаций.

Появление международных организаций стало не только ответом на развивающиеся культурные, политические, экономические отношения, которые оформляются вне рамок национальных государств, но и необходимостью для координации межгосударственных сил в решении транснациональных задач[1].

Поэтому, анализируя документы Форума, как замечает А.Н. Чумаков, проблемы глобального масштаба для Китая не являются первостепенными, так как акцент сделан на гуманитарной сфере, в частности на культуре и общественных отношениях[12]. Он объясняет это тем, что культура, традиции, возможности диалога интересуют китайцев больше, когда речь идет об экономике, перспективах развития внутренней и внешней политики. При этом, А.Н. Чумаков замечает, что вопросы гуманизации культуры китайцы демонстрируют и тогда, когда речь идет об осмыслении протекающих современных процессов глобализации[12].

Неслучайно, что World Cultural Forum [Taihu, China] явился прообразом Давосского мирового экономического форума, заявив, что диалог и сотрудничество - основа мировой гармонии, так как все проблемы кроются в поведении и в ментальности человека, которые должны быть согласованы с глобализирующимся миром. А.Н. Чумаков заключает, что китайцы первыми «увидели новые возможности там, где их еще пока никто по-настоящему не видит». Это - кризис культуры и духовности, нравственности общества. Китайцы в соответствии с заветами 


\section{Social Science and Humanity \#3 2016}

Дэн Сяопина «хладнокровно наблюдают», «уверенно реагируют на изменения», «делают конкретные дела» и «укрепляют позиции», тогда как в техногенных культурно-цивилизационных системах еще не обращают должного внимания на гуманитарную сферу и по-настоящему в нее не вкладываются[12].

И можно считать, что утверждение о социообразующей роли нравственности, духовности и культуры, прозвучавшее на Форуме, может стать программным документом в рамках глобализирующейся культуры.

А.Н. Чумаков приводит основные позиции, которые были отмечены в Декларации Форума, получившей название «Шанхайский консенсус»[13]. К ним относится следующее.

В условиях изменяющегося мира, обострения глобальных проблем, когда человечество «становится сообществом единой судьбы», необходимо «обеспечить продвижение мира и развития в духе взаимного уважения, гармонизацию без унификации».

В Декларации отмечено, что в условиях деструктивных политических процессов становится важным «активизация культурного обмена (усиление культурного взаимодействия на основе «мягкой силы»), упрочение взаимопонимания и доверия между народами всех наций с целью поощрения более широкого международного политического и экономического сотрудничества, укрепления мира и развития».

Декларация Культурного форума делает акцент на культурном обмене и взаимном обучении, которые возможны при условии «уважения культурного разнообразия», по вопросам которого, как отмечено в Декларации, уже «сложился международный консенсус».

Таким образом, стоит заметить, что прошедший Форум не столько определил, сколько продолжил концепцию гармоничного развития, но уже на уровне мировой общественности, в том числе и для деятельности международных организаций.

Ильин Н.В. и М.А. Каверин, рассматривая деятельность международных организаций, считают необходимым[14] рассматривать их в рамках глобального управления, так как оно представлено «в контексте процессов глобализации и становления глобального сообщества, в котором формируются соответствующие институты регулирования».

Как замечает В.С. Степин, в условиях глобализации для культурного взаимодействия, диалога культур и цивилизаций создаются новые перспективы, которые способствуют не только сохранению фрагментов традиционных культур, но адаптации к новым ценностям[15].

B.C. Степин анализирует две возможных стратегии взаимодействия культур в условиях глобализации, где к первой он относит культурное взаимодействие стран, находящихся на неравнозначном экономическом положении, а ко второй стратегии - стратегию 


\section{Social Science and Humanity \#3 2016}

партнерства. В первом случае речь идет о принятии ценностей высокоразвитой культуры менее развитыми странами. А во втором диалог культур построен между равноправными партнерами, которые стремятся не только уважать, но и сохранять культурные традиционные ценности друг друга. И это является уже условием для порождения новых ценностей.

Поэтому В.С. Степин отмечает далее, что они (новые ценности), определяя зарождение новых мировоззренческих смыслов, должны быть не только воспринимаемы всеми культурами (вступающими в новый диалог), но и способствовать сохранению традиционной ментальности[14]. Это ведет и к изменению политического сознания, а следовательно, и к новой трактовке диалога культур - политическому диалогу.

И здесь стоит остановиться на замечании немецкого философа К.Х. Пола, что в современных условиях, когда речь идет о формировании новых ценностей, то речь должна идти не об универсальных, а о договорных ценностях[16], что позволит разным культурам быть открытыми друг для друга.

В рамках данного исследования представляет несомненный интерес концепция региональной глобализации О.Г. Леоновой, осмысление которой построено на том, что в условиях глобализации происходит формирование региональных объединений (союзов) различных государств, которые не столько имеют общие границы, сколько общие интересы для достижения своих целей[17].

Так как глобализацию сопровождает процесс регионализации в сфере международных отношений, то сегодня, по мнению О.Г. Леоновой, не только сформировались мировые центры (АСЕН, АТЭЕС и др.), которые характеризуются экономической интеграцией, но и зарождаются макрорегионы, как динамически развивающиеся системы, приобретающиеся признаки глобальности. К ним О.Г. Леонова относит и Шанхайская организация сотрудничества[17].

Будучи политологом О.Г. Леонова определяет природу глобальной регионализации и к ее характеристике она относит следующие позиции:

- локальные сообщества интегрируются в макрорегионы на основе экономического сотрудничества, социокультурной близости и т.п. для решения стратегии глобального мира;

- локализация регионального сообщества имеет границы, которые чаще всего совпадают с границами государств;

- интеграция и локализация способствуют возникновению новому геополитическому образованию (в форме союзов, объединений и т.п.)[17].

Вывод 


\section{Social Science and Humanity \#3 2016}

Таким образом, отмечаем, что процесс глобальной регионализации в форме проявления ШОС - находится в стадии становления, развития, что еще раз подтверждает правомочность рассмотрения деятельность ШОС в контексте глобализирующейся культуры. Представление о динамике глобализирующейся культуры как одного из фактора строительства гармоничного общества, представлено в материалах Всемирного культурного форума, который проходил в КНР.

Сегодня глобализирующаяся культура может быть представлена как понятие или как идея, что позволяет рассмотреть ее с позиций гносеологического и онтологического анализа как продукт XX I века; следовательно - это явление, отражающее нормы и принципы, ценностные ориентации поведения и отношения к миру - пространству совместного гармоничного проживания с позиций общечеловеческой безопасности.

Процесс глобализации охватывает все сферы деятельности человека. Китайские ученые представляют глобализацию как шаг к глобализации культуры в виде цикличности и взаимосвязи, где одно порождает другое. Но при этом они делают акцент на том, что экономическая глобализация как основа глобализации культуры, направлена на то, чтобы обеспечивать равные условия для всех, что становится возможным благодаря политическому диалогу.

\section{References:}

[1] Chumakov A.N. On the subject and borders of the global // The age of globalization. № 1. 2008 - p.7-18

[2] Chumakov A.N. The modern world: on the threshold of a fundamental transformation // The age of globalization. № 2. 2008. - p.93

[3] Kolesnikov V.A. From understanding globalized reality - to a new vision of education of the XXI century // The age of globalization. № 1. 2009

[4] Chumakov A.N. Theoretical and methodological bases of research of processes of globalization // The age of globalization. № 2. 2013. p.29

[5] Gei Y.. The processes of globalization and science of globalistics // The age of globalization. № 1.2008. - p.30

[6] Malukova O.V. Philosophical and methodological research of globalization // The age of globalization. №1.2008 - p168-169

[7] Cheshkov M.A. Worldwide As a basic concept of global // The age of globalization. № 2.2008. -p.4-10

[8] Barlibaev H.A. Globalization: Theory and Practice // The age of globalization. № 2.2008. - p.14

[9] Markovish D.V A culture of peace, tolerance and inter-ethnic relations // The age of globalization. № 2 . 2008. - p.155 


\section{Social Science and Humanity \#3 2016}

[10]Mezuev V.M. Culture of Philosophy in the modern system of knowledge // Personality. Culture. Society.2004. - .2 (22) - p.136-154

[11] Scheglov V.V. The globalizing world and culture. - Proceedings of the Volgograd State Pedagogical University, 2012.- № 11. T.75. - p.166

[12] Chumakov A.N. Cultural and civilizational fractures global peace // The age of globalization. № 2. 2015. - p.35-47

[13] Chumakov A.N. "Soft power" as a way of solving problems in a globalized world // The age of globalization. № 2. 2014 - p.192

[14]Ilin I.V.. Questions of the transformation of international organizations in the global institutions of governance // The age of globalization. № 2. 2014. - p.32-38

[15] Stepen V,S.. Globalization and Dialogue of Cultures: the problem of values // The age of globalization. № 2 . 2011. - p.8-9

[16]Pol K.H.. Chinese and Western values: Reflections on the methodology of intercultural dialogue // The age of globalization. № 1 . 2012. - p.102

[17]Leonova O.G.. Global regionalization as a phenomenon of global peace // The age of globalization. № 1. 2013. - p.59 -68

Статья выполнена в рамках гранта для государственной поддержки молодых российских ученых (кандидатов наук) Совета по грантам Президента РФ МК- 3682.2015 .6 